\title{
Potencial reprodutivo de touros da raça Nelore submetidos a diferentes proporções touro:vaca
}

[Reproductive potential of Nelore bulls submitted to different bull:cow proportion]

\author{
M.D. Santos ${ }^{1 *}$, C.A.A. Torres ${ }^{2}$, J.R.M. Ruas ${ }^{3}$, J.D. Guimarães ${ }^{2}$, J.M. Silva Filho ${ }^{4}$ \\ ${ }^{1}$ Universidade de Cuiabá - UNIC \\ ${ }^{2}$ Universidade Federal de Viçosa - Viçosa, MG \\ ${ }^{3}$ Pesquisador da EPAMIG - Viçosa, MG \\ ${ }^{4}$ Universidade Federal de Minas Gerais - Belo Horizonte, MG
}

\begin{abstract}
RESUMO
Estudou-se o potencial reprodutivo de 20 touros da raça Nelore, submetidos a diferentes proporções touro:vaca, e foram estimadas as correlações entre concentração de testosterona, circunferência escrotal, qualidade seminal e libido. Os touros, selecionados via exame andrológico e teste da libido, foram distribuídos nas seguintes proporções (tratamentos) touro:vaca: 1:25 (T1), 1:50 (T2), 1:75 (T3) e 1:100 (T4), com cinco repetições em cada tratamento. Amostras de sangue foram coletadas para determinação da concentração de testosterona. Aspectos físicos e morfológicos do sêmen, circunferência escrotal e libido dos touros não foram influenciados pelos tratamentos. Não houve efeito da proporção touro:vaca sobre a taxa de gestação das vacas, cujas médias foram de 42,1; 66,5; e 71,0\% aos 30, 60 e 90 dias de estação de monta, respectivamente. A concentração de testosterona não diferiu entre os tratamentos, média de 4,04ng/ml de soro, com pico de testosterona às 9 horas. Correlações entre libido, características físicas e morfológicas do sêmen e circunferência escrotal dos touros foram baixas. Touros da raça Nelore com boa qualidade seminal e libido suportaram elevado número de vacas e a proporção de 1:100 não reduziu a taxa de gestação.
\end{abstract}

Palavras-chave: exame andrológico, fertilidade, libido, proporção touro:vaca, testosterona

\begin{abstract}
This study evaluated the reproductive potential of 20 Nelore bulls, submitted to different bull:cow ratio. Correlations among the serum testosterone concentration, scrotal circumference, sperm quality and libido were also estimated. The bulls selected by andrologic evaluation and the libido test were alloted to the following bull:cow ratio (treatments): 1:25 (T1), 1:50 (T2), 1:75 (T3) e 1:100 (T4), with five replicates per treatment. Blood samples were collected to determine serum testosterone concentration. Semen physical and morphologic characteristics, scrotal circumference and libido of the bulls did not differ among treatments. The pregnancy rate of the cows was not affected by treatments (means of 42.1, 66.5 and $71.0 \%$ for breeding season of 30, 60 and 90 days, respectively). The testosterone concentration was not affected by treatments and the mean serum testosterone concentration was $4.04 \mathrm{ng} / \mathrm{ml}$, which peaked at 9am. The correlations between the libido, semen physical and morphologic characteristics, and the scrotal circumference of the bulls were low. Nelore bulls with good sperm quality and libido supported a large number of cows, and the bull:cow ratio of 1:100 did not reduce the pregnancy rate.
\end{abstract}

Keywords: andrologic evaluation, bull:cow ratio, fertility, libido, testosterone

\section{INTRODUÇÃO}

Recebido para publicação em 23 de fevereiro de 2003

Recebido para publicação, após modificações, em 4 de junho de 2004

*Endereço para correspondência:

Rua das Pérolas, n.184, cond. Bosque da Saúde, Apto 703B - 78050-090 - Cuiabá, MT

E.mail: dinizms@uol.com.br 
No Brasil, predomina na espécie bovina o acasalamento por monta natural, responsável por mais de 95\% dos bezerros nascidos. Tradicionalmente, os pecuaristas adotam a proporção touro:vaca de 1:25 que, segundo Fonseca et al. (1996) e Fonseca et al. (2000), resulta em subutilização dos touros e, conseqüentemente, torna a monta natural uma prática antieconômica.

Diversos estudos têm sido realizados no Brasil visando aumentar a proporção touro:vaca para $1: 40,1: 60,1: 80,1: 92$ ou mesmo 1:96, com o objetivo de maximizar o potencial reprodutivo dos touros, a fim de aumentar a eficiência reprodutiva do rebanho e reduzir os custos (Fonseca et al., 1991; Pineda e Lemos, 1994; Pineda et al., 1997a,b; Galvani, 1998; Fonseca et al., 2000), contudo, os dados obtidos ainda não são conclusivos.

De acordo com Fonseca et al. (1996) e Fonseca et al. (2000), a alteração na tradicional proporção touro:vaca de 1:25 para 1:60 e 1:80 acarreta redução no custo de cada bezerro desmamado de 18,6 e $22,8 \%$, respectivamente, que tende a aumentar com o número de matrizes.

Fonseca et al. (1996), ao utilizarem touros classificados como questionável e de alta habilidade de monta, na proporção touro:vaca de $1: 80$, obtiveram 68,8 e $88,8 \%$ de taxa de gestação aos 63 dias de estação de monta, respectivamente. Os altos índices de gestação obtidos mostram que touros bons no exame andrológico e com habilidade de monta muito alta permitem reduzir, sensivelmente, o tempo de estação de monta, sem interferir na fertilidade do rebanho.

Segundo Blockey e Galloway (1978), a testosterona é necessária à manutenção da capacidade de serviço em touros. Para Chenoweth (1983), a libido aparentemente não está relacionada com as características seminais ou a circunferência escrotal, sendo possível obter sêmen de boa qualidade de animais com baixa libido ou vice-versa. Hafez et al. (2000) relataram que a manutenção das características sexuais secundárias, do comportamento sexual ou da libido do macho também é controlada pelos andrógenos.
Correlações têm sido estimadas entre concentração sangüínea de testosterona e fertilidade. Post e Christensen (1976), ao trabalharem com touros mestiços, verificaram maior concentração de testosterona naqueles com maior taxa de fertilidade, avaliadas pelo número de vacas gestantes. Andersson (1992) encontrou correlação positiva entre a concentração de testosterona sérica e a fertilidade de touros, avaliada pela taxa de não-retorno. Barbosa et al. (1991) e Fonseca et al. (1996) verificaram correlações de 0,84 e 0,62 , respectivamente, entre libido e capacidade de serviço de touros da raça Nelore, sugerindo que o teste da libido seria a alternativa mais viável para avaliar o comportamento sexual.

Estudos realizados por Fonseca et al. (1996), Pineda et al. (1997a,b) e Santos (2000) enfocaram a qualidade do sêmen, a circunferência escrotal, o comportamento sexual de touros e as diferentes proporções touro:vaca visando reduzir o custo de manejo reprodutivo e maximizar o potencial reprodutivo dos machos. Considerando que os resultados obtidos, até o momento, não foram conclusivos, os objetivos deste trabalho foram estudar $o$ potencial reprodutivo de touros da raça Nelore submetidos às proporções touro:vaca de 1:25, 1:50, 1:75 e 1:100 sobre a fertilidade do rebanho, avaliada pela taxa de gestação, e verificar possíveis correlações entre concentração sérica de testosterona, circunferência escrotal, qualidade seminal e comportamento sexual dos touros.

\section{MATERIAL E MÉTODOS}

O experimento foi desenvolvido na Fazenda Santa Cristina, localizada no município de Santo Antônio do Leste - MT, no período de outubro de 1997 a maio de 1998 .

As pastagens cultivadas eram formadas com predominância de capim braquiarão (Brachiaria brizantha). Do rebanho de 5.300 matrizes e 230 touros da raça Nelore, foram selecionados os animais utilizados no presente experimento, mantidos no manejo normal da fazenda, com mistura mineral completa, à vontade, em cochos coletivos.

Os touros da raça Nelore, devidamente identificados, clinicamente normais, entre 7 e 10 
anos de idade, foram inicialmente selecionados por meio de avaliação andrológica, que consistiu de: exame dos órgãos genitais internos com palpação transretal das ampolas dos ductos deferentes e das glândulas vesiculares, e exames do prepúcio, do pênis e dos testículos e epidídimos, observando-se a forma, o tamanho, a posição, a simetria e a consistência de cada órgão. Em seguida, foi feita a mensuração da circunferência escrotal na região de maior diâmetro dos testículos. O sêmen foi colhido por eletroejaculação, avaliando-se os aspectos físicos e a morfologia espermática, conforme Henry e Neves (1998). Os animais foram pesados após a colheita de sêmen, realizada no início e no final da estação de monta.

Uma semana após a avaliação andrológica, os touros foram selecionados com relação ao comportamento sexual, utilizando-se o teste da libido, conforme critérios preconizados por Chenoweth (1984), com escore variando de 0 a 10. Cada touro foi colocado em um piquete $\left( \pm 500 \mathrm{~m}^{2}\right)$, com duas vacas em estro induzido, durante 15 minutos. Para cada atitude dos touros frente às vacas foi atribuída pontuação, classificada como: libido questionável (0-3), libido boa (4-6), libido muito boa (7-8) e libido excelente (9-10) (Chenoweth, 1984). As vacas em estro foram substituídas a cada dois touros testados, ou quando necessário, para evitar recusa a novos serviços.

Dos 56 touros testados, 20 foram selecionados por apresentarem libido muito boa a excelente (7-10). Eles foram distribuídos aleatoriamente, em acasalamento coletivo, em quatro tratamentos (T), com base nas seguintes proporções touro:vaca: $\mathrm{T} 1=1: 25$ (cinco touros para 125 vacas), $\mathrm{T} 2=1: 50$ (cinco touros para 250 vacas), $\mathrm{T} 3=1: 75$ (cinco touros para 375 vacas) e $\mathrm{T} 4=$ 1:100 (cinco touros para 500 vacas). Utilizaramse vacas da raça Nelore, aptas à reprodução e selecionadas por exame transretal, com idade média de oito anos e com bezerro ao pé.

Para determinação do efeito circadiano e da concentração sérica de testosterona colheram-se amostras de sangue de cada touro, quatro dias antes do início da estação de monta (janeiro/98), durante 24 horas, às 9, 13, 17, 21, 1 e 5h. As amostras foram submetidas a procedimentos de rotina para posteriores análises (Valle e Dode, 1991). O perfil de testosterona no soro foi determinado via radioimunoensaio (RIA) de fase sólida, com uso de kit comercial ${ }^{1}$.

A duração da estação de monta foi de 90 dias (janeiro a abril/98), tendo sido realizados rodeios diários nos primeiros 45 dias e a cada dois dias no período restante.

O diagnóstico de gestação foi feito por palpação transretal aos 60 dias após o início da estação de monta e a cada 30 dias, para a obtenção dos percentuais de fêmeas gestantes aos 30, 60 e 90 dias da estação de monta. As fêmeas gestantes foram mantidas em cada tratamento até o final da estação de monta, para não alterar as proporções touro:vaca.

Para avaliar o efeito da proporção touro:vaca sobre o percentual de vacas gestantes usou-se o teste qui-quadrado. Para avaliação da concentração sérica de testosterona utilizou-se o sistema de análises estatísticas e genéticas (Sistema..., 1997) aplicando-se a análise de variância para modelos lineares, em esquema de parcelas subdivididas, tendo nas parcelas os tratamentos e nas subparcelas as horas de avaliação, com cinco repetições. Para o estudo do efeito de período de avaliação foram testados modelos de regressão.

Para avaliar a qualidade do sêmen usou-se análise de variância para modelos lineares e o teste $\mathrm{t}$ (dados pareados). Também foram estabelecidos coeficientes de correlação Pearson existentes entre concentração de testosterona, qualidade seminal, libido e circunferência escrotal.

\section{RESULTADOS E DISCUSSÃO}

Os aspectos físicos e morfológicos do sêmen, a circunferência escrotal e a libido dos touros no início da estação de monta não diferiram $(\mathrm{P}>0,05)$ entre os tratamentos (Tab. 1). Estes dados reforçam o critério utilizado para a seleção dos touros, visando obter homogeneidade das características avaliadas segundo os tratamentos.

\footnotetext{
${ }^{1}$ DPC COAT A COUNT. Total Testosterone. Los Angeles, USA.
} 
Tabela 1. Médias de turbilhonamento (Tur), motilidade espermática progressiva (Mot), vigor (Vig), concentração espermática (Con), defeitos espermáticos totais (Dft), circunferência escrotal (Ces) e libido (Lib) dos touros segundo os tratamentos, no início da estação de monta

\begin{tabular}{lccccccc}
\hline Tratamento & Tur & Mot $(\%)$ & Vig & Con $\left(10^{6} / \mathrm{ml}\right)$ & Dft $(\%)$ & Ces $(\mathrm{cm})$ & Lib \\
\hline T1 & 3,4 & 75,0 & 3,6 & 847 & 14,9 & 37,5 & 8,2 \\
T2 & 2,8 & 74,0 & 3,0 & 743 & 15,3 & 37,2 & 8,0 \\
T3 & 3,0 & 74,0 & 3,0 & 593 & 14,5 & 38,2 & 7,8 \\
T4 & 2,8 & 75,0 & 3,0 & 525 & 10,6 & 38,9 & 8,2 \\
\hline
\end{tabular}

$(\mathrm{P}>0,05)$ pelo teste $\mathrm{F}$.

$\mathrm{T} 1=$ proporção touro:vaca de 1:25; T2= proporção de 1:50; T3= proporção de 1:75; T4= proporção de 1:100.

Apesar de ter ocorrido redução $(\mathrm{P}<0,05)$ na motilidade espermática progressiva, no vigor, no turbilhonamento e na concentração espermática, os touros não perderam sua capacidade fecundante com relação à qualidade seminal, durante a estação de monta (Tab. 2). O percentual de defeitos espermáticos totais e a circunferência escrotal não foram alterados $(\mathrm{P}>0,05)$ durante o período.

Tabela 2. Médias de turbilhonamento (Tur), motilidade espermática progressiva (Mot), vigor (Vig), concentração espermática (Con), defeitos espermáticos totais (Dft) e circunferência escrotal (Ces) dos touros, avaliados no início e final da estação de monta (EM) Característica Início da EM Final da EM Diferença

\begin{tabular}{|c|c|c|c|}
\hline Tur & $3,0 \mathrm{a}$ & $2,2 b$ & $-0,8$ \\
\hline $\operatorname{Mot}(\%)$ & $74,5 \mathrm{a}$ & $57,2 b$ & $-17,3$ \\
\hline Vig & $3,1 \mathrm{a}$ & $2,4 \mathrm{~b}$ & $-0,7$ \\
\hline Con $\left(10^{6} / \mathrm{ml}\right)$ & $668,2 \mathrm{a}$ & $418,0 \mathrm{~b}$ & $-250,2$ \\
\hline $\operatorname{Dft}(\%)$ & 13,8 & 15,3 & $+1,5$ \\
\hline Ces $(\mathrm{cm})$ & 37,9 & 37,7 & $-0,2$ \\
\hline
\end{tabular}

$\mathrm{Na}$ Tab. 3 encontra-se a eficiência reprodutiva dos touros de cada tratamento, avaliada pelas taxa de gestação das fêmeas, aos 30, 60 e 90 dias após o início da estação de monta. A proporção touro:vaca não influenciou $(\mathrm{P}>0,05)$ a taxa de gestação (médias de 42,1; 66,5; e 71,0\% aos 30, 60 e 90 dias de estação de monta, respectivamente). Estes resultados foram inferiores aos observados por Costa Silva et al. (1993), que utilizaram proporções touro:vaca de $1: 37$ e 1:54 e obtiveram taxas de gestação de 66,4 e $66,7 \%$ (30 dias), 84,2 e 89,3\% (60 dias) e 91,4 e $94,2 \%$ (90 dias de estação de monta), respectivamente, e por Fonseca et al. (1997), que utilizaram proporções de 1:40 e 1:60 e registraram taxas de gestação de 48,3 e $59,6 \%$ (30 dias), 78,3 e 91,3\% (60 dias) e 87,7 e 95,0\% (90 dias de estação de monta), respectivamente. Essas diferenças podem ser explicadas, em parte, pela utilização de vacas solteiras pelos autores citados, as quais sem a presença do bezerro podem alterar o seu comportamento reprodutivo hormonal em relação às com bezerro ao pé. Além disso, diferenças na fertilidade do solo e na qualidade das pastagens podem resultar em diferentes taxas de gestação.

Tabela 3. Taxa de gestação de vacas aos 30, 60 e 90 dias de estação de monta, submetidas a touros da raça Nelore, segundo a proporção touro:vaca

\begin{tabular}{|c|c|c|c|c|c|c|c|c|}
\hline \multirow{2}{*}{$\begin{array}{l}\text { Proporção } \\
\text { touro:vaca }\end{array}$} & \multirow{2}{*}{$\begin{array}{l}\mathrm{N} \mathrm{de} \\
\text { touros }\end{array}$} & \multirow{2}{*}{$\begin{array}{l}\mathrm{N} \text { de } \\
\text { vacas }\end{array}$} & \multicolumn{2}{|c|}{30 dias } & \multicolumn{2}{|c|}{60 dias } & \multicolumn{2}{|c|}{90 dias } \\
\hline & & & $\mathrm{N}$ & $\%$ & $\mathrm{~N}$ & $\%$ & $\mathrm{~N}$ & $\%$ \\
\hline $1: 25$ & 05 & 125 & 52 & 41,6 & 83 & 66,4 & 90 & 72,0 \\
\hline $1: 50$ & 05 & 250 & 104 & 41,6 & 164 & 65,6 & 175 & 70,0 \\
\hline $1: 75$ & 05 & 375 & 178 & 47,4 & 262 & 69,8 & 283 & 75,4 \\
\hline $1: 100$ & 05 & 500 & 192 & 38,4 & 322 & 64,4 & 340 & 68,0 \\
\hline Total & 20 & 1250 & 526 & 42,1 & 831 & 66,5 & 888 & 71,0 \\
\hline
\end{tabular}

Diferença entre valores não significativa pelo teste $\chi^{2}(\mathrm{P}>0,05)$. 
Todas as taxas de gestação já citadas e as obtidas por Costa Silva (1995), Fonseca et al. (1997), Pineda et al. (1997a), Galvani (1998) e Fonseca et al. (2000) mostram que os resultados não são conclusivos, pois as proporções utilizadas podem ainda não ser desafiantes. Assim, touros da raça Nelore podem suportar maior número de vacas em estação de monta de 90 dias, o que certamente tornaria o sistema de acasalamento mais eficiente e econômico.

Segundo Pineda et al. (1997a), a proporção touro:vaca de 1:92 e a respectiva taxa de gestação de $56 \%$ aos 21 dias de estação de monta resultaram em prolongamento da estação de nascimento e afetou a eficiência reprodutiva do rebanho, pois aumentou o período de serviço e, conseqüentemente, o intervalo de partos. Isso não foi evidenciado neste estudo.
Ocorreu redução $(\mathrm{P}<0,01)$ de peso dos touros (média de $9,1 \%$ ou $0,680 \mathrm{~kg} / \mathrm{dia}$ ) durante a estação de monta (Tab. 4). Ela foi maior que a observada por Pineda et al. (1997a), que verificaram redução de apenas 5\% em relação ao peso inicial, em estação de 63 dias, ao utilizarem a proporção touro:vaca de 1:92. Os touros mantidos na proporção 1:75 perderam mais peso $(-71 \mathrm{~kg} ; \quad \mathrm{P}<0,05)$ do que os mantidos na proporção 1:25 $(-52 \mathrm{~kg})$. As perdas de peso nas proporções 1:50 e 1:100 foram intermediárias $(\mathrm{P}>0,05)$ e semelhantes às outras perdas. Fatores como manejo e qualidade das pastagens, duração da estação de monta, ocorrência de chuva, entre outros, podem interferir nessa variação de peso durante o período de estação de monta.

Tabela 4. Peso médio e variação de peso de touros da raça Nelore, segundo a proporção touro:vaca, durante os 90 de estação de monta

\begin{tabular}{lcccc}
$\begin{array}{l}\text { Proporção } \\
\text { touro:vaca }\end{array}$ & $\begin{array}{c}\text { Peso } \\
\text { inicial }(\mathrm{kg})\end{array}$ & $\begin{array}{c}\text { Peso } \\
\text { final }(\mathrm{kg})\end{array}$ & $\begin{array}{c}\text { Variação de peso }(\mathrm{kg}) \\
\text { no período }\end{array}$ & $\begin{array}{c}\text { Variação de peso }(\mathrm{kg}) \\
\text { diário }\end{array}$ \\
\hline $1: 25$ & 670 & 618 & $-52 \mathrm{~B}$ & $-0,57$ \\
$1: 50$ & 649 & 592 & $-57 \mathrm{AB}$ & $-0,63$ \\
$1: 75$ & 679 & 608 & $-71 \mathrm{~A}$ & $-0,79$ \\
$1: 100$ & 682 & 617 & $-65 \mathrm{AB}$ & $-0,72$ \\
Média & 670 & 609 & -61 & $-0,68$ \\
\hline
\end{tabular}

Médias seguidas por letras distintas na coluna diferem entre si $(\mathrm{P}<0,05)$ pelo teste Tukey.

A concentração sérica de testosterona não diferiu $(\mathrm{P}>0,05)$ entre os tratamentos. Os animais apresentaram concentração média de testosterona de 4,04ng/ml, com amplitude de variação de 0,80 a $16,07 \mathrm{ng} / \mathrm{ml}$. Houve efeito $(\mathrm{P}<0,01)$ do horário de colheita das amostras de sangue sobre a concentração de testosterona. Entretanto, os modelos testados de regressão da concentração de testosterona em função da hora de colheita apresentaram coeficientes de regressão muito baixos (linear, $\mathrm{r}^{2}=0,0016$; quadrático, $\mathrm{r}^{2}=0,42 \mathrm{e}$ cúbico, $\left.\mathrm{r}^{2}=0,43\right)$. Não houve interação $(\mathrm{P}>0,05)$ tratamentos versus hora de observação; o pico de testosterona ocorreu na colheita das 9h (Fig. 1).

Sanwal et al. (1974) observaram em touros Bos taurus taurus, com dois anos de idade, picos de testosterona em torno das 6, 12 e 22h. Segundo os autores, eles podem estar relacionados ao estado sexual, manejo, temperatura e fotoperíodo a que os animais estão submetidos.

As correlações entre a libido e as características físicas e morfológicas do sêmen e a circunferência escrotal dos touros foram baixas (Tab. 5). Resultados semelhantes foram encontrados por Pineda e Lemos (1994), Fonseca et al. (1996) e Santos (2000), o que reforça a necessidade de mais estudos com relação a aplicabilidade do teste da libido em touros zebu, já que o método existente foi desenvolvido para touros europeus. Além disso, o teste da libido deve ser um complemento ao exame andrológico que se faz antes do início da estação de monta, auxiliando no diagnóstico de problemas inerentes à cópula ou mesmo à incapacidade de realizá-la. 


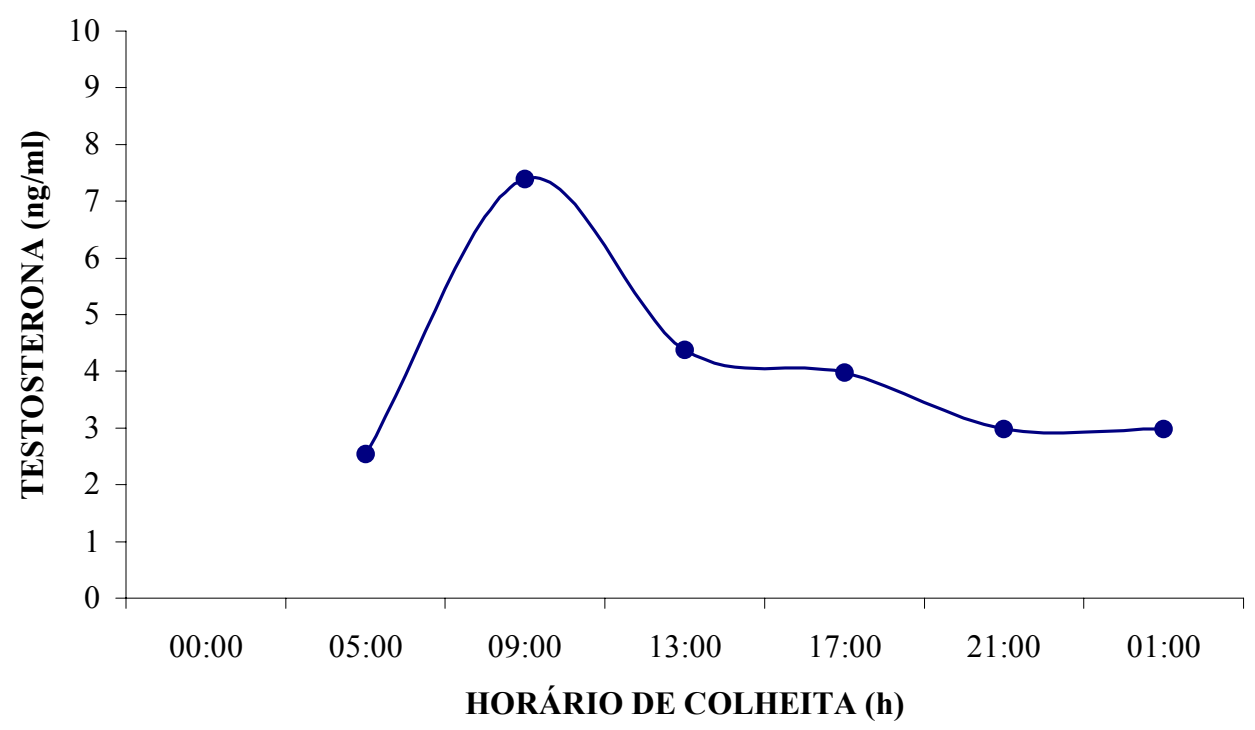

Figura 1. Concentração sérica de testosterona em touros da raça Nelore segundo a hora de colheita, no período de 24 horas.

Tabela 5. Coeficientes de correlação de Pearson entre circunferência escrotal (Cir), turbilhonamento (Tur), motilidade espermática progressiva (Mot), vigor (Vig), concentração espermática (Con), defeitos espermáticos totais (Dft), libido (Lib) e concentração sérica de testosterona (Test) de touros Nelore

\begin{tabular}{lccccccc} 
Característica & Tur & Mot & Vig & Con & Dft & Lib & Test \\
\hline Cir & $-0,17$ & $-0,04$ & $-0,12$ & $-0,17$ & 0,00 & $-0,07$ & $-0,28$ \\
Tur & & $0,59^{* *}$ & $0,68^{* *}$ & $0,42^{*}$ & $-0,44^{*}$ & 0,18 & 0,32 \\
Mot & & $0,69^{* *}$ & 0,26 & $-0,36$ & 0,29 & 0,25 \\
Vig & & & 0,31 & $-0,34$ & 0,24 & 0,04 \\
Con & & & & & $-0,28$ & $0,38^{*}$ & 0,18 \\
Dft & & & & & $-0,41^{*}$ & $-0,38^{*}$ \\
Lib & & & & & & $0,41^{*}$ \\
\hline${ }^{* *} \mathrm{P}<0,01$ e ${ }^{*} \mathrm{P}<0,05$ pelo teste t. & & & & & &
\end{tabular}

A concentração sérica de testosterona, apesar de correlacionada $\quad(\mathrm{P}<0,05) \quad$ com defeitos espermáticos totais $(-0,38)$ e com libido $(0,41)$ (Tab. 5), foi relativamente baixa. Barbosa (1987) não observou correlação entre a concentração plasmática de testosterona e a libido e qualidade seminal de touros da raça Nelore.

\section{CONCLUSÕES}

As proporções touro:vaca utilizadas não interferiram na taxa de gestação das fêmeas; a proporção touro:vaca de 1:100 não reduziu a taxa de gestação das vacas aos 30, 60 e 90 dias de estação de monta; foram baixas as correlações entre libido, características físicas e morfológicas do sêmen e circunferência escrotal.

\section{REFERÊNCIAS BIBLIOGRÁFICAS}

ANDERSSON, M. Relationships between GnRHinduced testosterone maxima, sperm motility and fertility in Ayrshire bulls. Anim. Reprod. Sci., v.27, p.107-111, 1992. 
BARBOSA, R.T. Comportamento sexual, biometria testicular, aspectos do sêmen e niveis plasmáticos de testosterona em touros Canchim e Nelore. 1987. 135f. Tese (Mestrado) - Escola de Veterinária, Universidade Federal de Minas Gerais, Belo Horizonte.

BARBOSA, R.T.; ALENCAR, M.N.; BARBOSA, P.F. et al. Comportamento sexual de touros das raças Canchim e Nelore. Rev. Bras. Reprod. Anim., v.5, p.151-157, 1991.

BLOCKEY, M.A.B.; GALLOWAY, D.B. Hormonal control of serving capacity in bulls. Theriogenology, v.9, p.143-151, 1978.

CHENOWETH, P.J. Examination of bulls for libido and breeding ability. Vet. Clin. North Am.: Anim. Pract., v.5, p.59-74, 1984.

CHENOWETH, P.J. Sexual behavior of the bull: a review. J. Dairy Sci., v.66, p.173-179, 1983.

COSTA SILVA, E.V. Limites dos touros da raça Nelore - O desafio da fertilidade. In: SIMPÓSIO O NELORE DO SÉCULO XXI, 3., 1995, Ribeirão Preto. Anais... Ribeirão Preto, 1995. p.39-43.

COSTA SILVA, E.V.; FONSECA, V.O.; HERMANY, A. et al. Avaliação andrológica de touros Nelore e aptidão reprodutiva: taxa de gestação. Rev. Bras. Reprod. Anim., v.17, p.97-109, 1993.

FONSECA, O.P.; PINEDA, N.R.; PROENÇA, R.V. Libido, capacidade de serviço e potencial reprodutivo de touros da raça Nelore (Bos taurus indicus) em estação de monta curta, utilizando a proporção touro:vaca 1:50 e 1:80. In: CONGRESSO BRASILEIRO DAS RAÇAS ZEBUÍNAS, 2., 1996, Uberaba. Anais... Uberaba: ABCZ, 1996, p.21-22.

FONSECA, V.O.; CRUDELI, G.A.; COSTA e SILVA, E.V. Potencial reprodutivo de touros da raça Nelore (Bos taurus indicus) em monta natural: proporção touro:vaca 1:40 e fertilidade. Rev. Bras. Reprod. Anim., v.15, p.103-108, 1991.

FONSECA, V.O.; FRANCO, C.S.; BERGMANN, J.A.G. et al. Potencial reprodutivo de touros da raça Nelore (Bos taurus indicus) acasalados com elevado número de vacas. Arq. Bras. Med. Vet. Zootec., v.49, p.53-62, 1997.

FONSECA, V.O.; FRANCO, C.S.; BERGMANN, J.A.G. Potencial reprodutivo e econômico de touros Nelore acasalados coletivamente na proporção de um touro para 80 vacas. Arq. Bras. Med. Vet. Zootec.,v.52, p.77-82, 2000.
GALVANI, F. Desempenho reprodutivo de touros de alta libido da raça Nelore. 1998. 76f. Tese (Mestrado) - Departamento de Medicina Veterinária, Universidade Federal de Viçosa, Viçosa, MG.

HAFEZ, E.S.E.; JAINUDEEN, M.R.; ROSNINA, Y. Hormones, growth factors, and reproduction. In: HAFEZ, E.S.E.; HAFEZ, B. Reproduction in farm animals. 7.ed. Philadelphia: Lea \& Febiger, 2000. 509p. Chap.3, p.33-54.

HENRY, M.; NEVES, J.P. Manual para exame andrológico e avaliação de sêmen animal. 2.ed. Belo Horizonte: Colégio Brasileiro de Reprodução Animal, 1998. 49p.

PINEDA, N.; FONSECA, V.O.; PROENÇA, R.V. Potencial reprodutivo de touros de alta libido da raça Nelore (Bos taurus indicus). Rev. Bras. Reprod. Anim., v.2, p.45-48, 1997a.

PINEDA, N.R.; LEMOS, P.F. Contribuição ao estudo da influência da libido e capacidade de serviço sobre a taxa de concepção em Nelore. Bol. Ind. Anim., v.51, p.61-68, 1994.

PINEDA, N.R.; LEMOS, P.F.; FONSECA, V.O. Comparação entre dois testes de avaliação do comportamento sexual (libido) de touros Nelore (Bos taurus indicus). Rev. Bras. Reprod. Anim., v.21, p.29-34, 1997b.

POST, T.B.; CHRISTENSEN, H.R. Testosterone variability and fertility in bulls. Theriogenology, v.6, p.615-616, 1976.

SANTOS, M.D. Comportamento sexual, qualidade seminal e eficiencia reprodutiva de touros da raça Nelore em regime de monta natural. 2000. 88f. Tese (Doutorado) - Departamento de Zootecnia, Universidade Federal de Viçosa, Viçosa, MG.

SANWAL, P.C.; SUNDBY, A.; EDQVIST, L.E. Diurnal variation of peripheral plasma levels of testosterone in bulls measured by a rapid radioimmunoassay procedure. Acta Vet. Scand., v.15, p.90-99, 1974.

SISTEMA de análises estatísticas e genéticas SAEG. Versão 7.1.Viçosa: UFV, 1997. 150p.

VALLE, E.R.; DODE, M.A.N. Efeito do tempo e da temperatura, entre a coleta e a centrifugação na concentração de progesterona do soro e do plasma de vacas Nelore. Pesq. Agropec. Bras., v.26, p.479485, 1991. 